\title{
Impedance-matched Marx generators
}

\author{
W. A. Stygar, ${ }^{1}$ K. R. LeChien, ${ }^{2}$ M. G. Mazarakis, ${ }^{1}$ M. E. Savage, ${ }^{1}$ B. S. Stoltzfus, ${ }^{1}$ K. N. Austin, ${ }^{1}$ \\ E. W. Breden, ${ }^{1}$ M. E. Cuneo, ${ }^{1}$ B. T. Hutsel, ${ }^{1}$ S. A. Lewis, ${ }^{1}$ G. R. McKee, ${ }^{1}$ J. K. Moore, ${ }^{1}$ \\ T. D. Mulville, ${ }^{1}$ D. J. Muron, ${ }^{1}$ D. B. Reisman, ${ }^{1}$ M. E. Sceiford, ${ }^{1}$ and M. L. Wisher ${ }^{1}$ \\ ${ }^{1}$ Sandia National Laboratories, Albuquerque, New Mexico 87185, USA \\ ${ }^{2}$ Lawrence Livermore National Laboratory, Livermore, California 94550, USA \\ (Received 26 September 2016; published 7 April 2017)
}

\begin{abstract}
We have conceived a new class of prime-power sources for pulsed-power accelerators: impedancematched Marx generators (IMGs). The fundamental building block of an IMG is a brick, which consists of two capacitors connected electrically in series with a single switch. An IMG comprises a single stage or several stages distributed axially and connected in series. Each stage is powered by a single brick or several bricks distributed azimuthally within the stage and connected in parallel. The stages of a multistage IMG drive an impedance-matched coaxial transmission line with a conical center conductor. When the stages are triggered sequentially to launch a coherent traveling wave along the coaxial line, the IMG achieves electromagnetic-power amplification by triggered emission of radiation. Hence a multistage IMG is a pulsed-power analogue of a laser. To illustrate the IMG approach to prime power, we have developed conceptual designs of two ten-stage IMGs with $L C$ time constants on the order of 100 ns. One design includes 20 bricks per stage, and delivers a peak electrical power of $1.05 \mathrm{TW}$ to a matched-impedance $1.22-\Omega$ load. The design generates $113 \mathrm{kV}$ per stage and has a maximum energy efficiency of $89 \%$. The other design includes a single brick per stage, delivers $68 \mathrm{GW}$ to a matched-impedance $19-\Omega$ load, generates $113 \mathrm{kV}$ per stage, and has a maximum energy efficiency of $90 \%$. For a given electrical-poweroutput time history, an IMG is less expensive and slightly more efficient than a linear transformer driver, since an IMG does not use ferromagnetic cores.
\end{abstract}

DOI: 10.1103/PhysRevAccelBeams.20.040402

\section{INTRODUCTION}

A linear-transformer-driver (LTD) module is an induction voltage adder that is powered by circuits located within the cavities of the adder [1-20]. Since an LTD module can be designed to provide single-stage electrical-pulse compression and impedance matching, such modules are attractive candidates as prime-power sources for nextgeneration pulsed-power accelerators [1-21].

Figures 1 and 2 are idealized representations of a tencavity LTD module. Figure 3 is an idealized circuit model of such a module. As suggested by Figs. 1-3, an LTD module consists of a single LTD cavity or several cavities distributed axially and connected electrically in series. Each cavity is a right-circular annular enclosure that contains a single LTD brick, or several bricks distributed azimuthally within the cavity and connected electrically in parallel. Each brick comprises a single switch and two capacitors connected in series.

The circuit model presented by Fig. 3 makes the following simplifying assumptions: each brick within the

Published by the American Physical Society under the terms of the Creative Commons Attribution 3.0 License. Further distribution of this work must maintain attribution to the author(s) and the published article's title, journal citation, and DOI.
LTD module is identical to every other brick, each LTD cavity includes the same number of bricks, all the bricks within a cavity are triggered simultaneously, and each brick can be modeled as an $R L C$ circuit. Under these conditions the quantities $R_{c}, L_{c}$, and $C_{c}$ of Fig. 3 are as follows:

$$
\begin{gathered}
R_{c}=\frac{R_{b}}{n_{b}}, \\
L_{c}=\frac{L_{b}}{n_{b}}, \\
C_{c}=n_{b} C_{b} .
\end{gathered}
$$

The quantity $R_{c}$ is the effective series resistance of a single cavity, $R_{b}$ is the effective series resistance of a single brick, $n_{b}$ is the number of bricks within each cavity, $L_{c}$ is the effective series inductance of a cavity, $L_{b}$ is the effective series inductance of a brick, $C_{c}$ is the series capacitance of a cavity, and $C_{b}$ is the series capacitance of a brick.

As indicated by Figs. 1-3, each LTD cavity includes ferromagnetic cores. These introduce an effective parallel resistance within a cavity $[7,13,15-20]$. For each cavity, Fig. 3 models the cores as a resistive circuit element with resistance $R_{\text {cores }}$ located at the cavity output [7,13,15-20].

As indicated by Figs. 1 and 2, the walls of a cavitywhich are conductors - connect the downstream electrode 


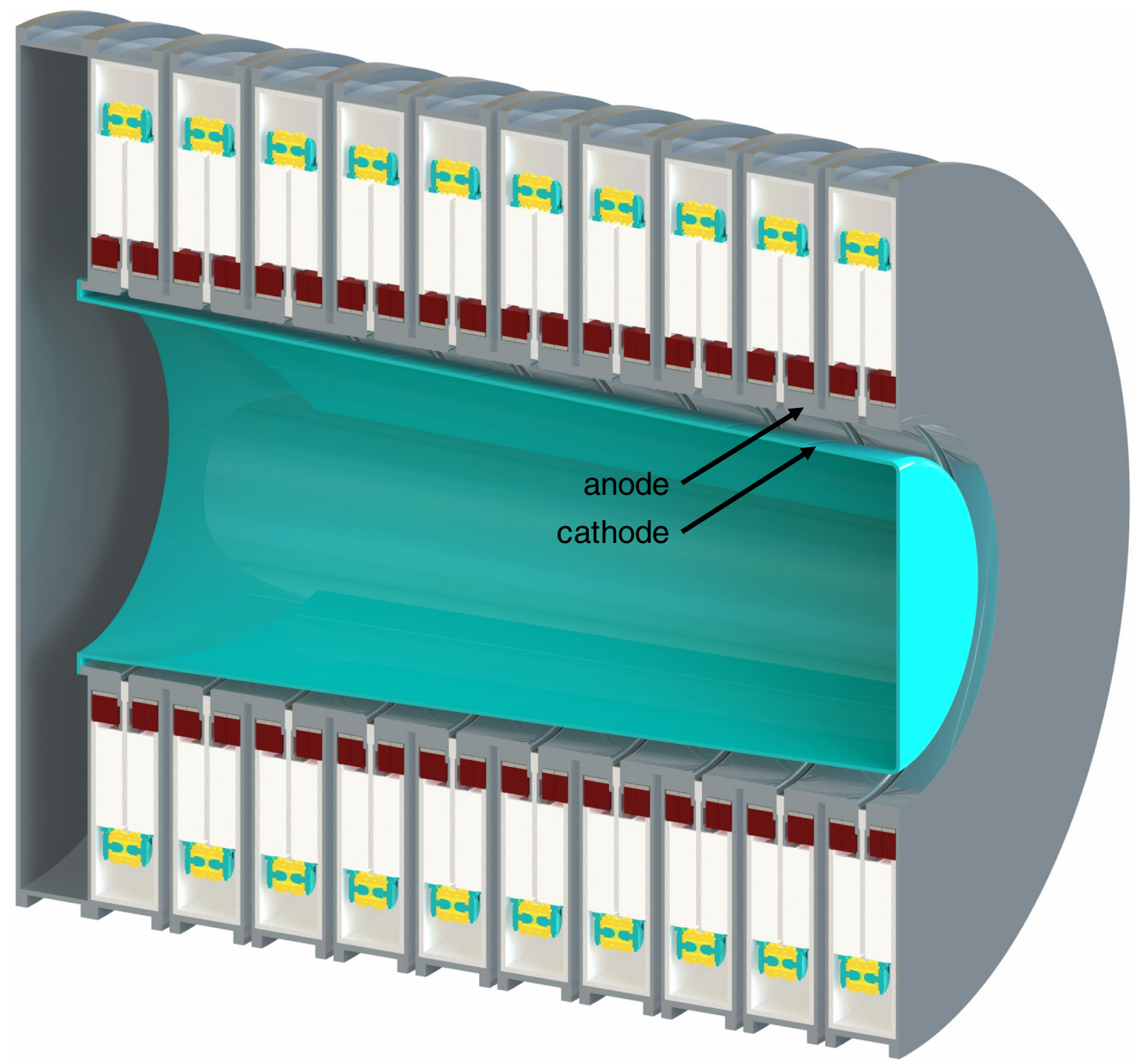

FIG. 1. Cross-sectional view of a ten-cavity linear-transformer-driver (LTD) module. The module is powered by 200 bricks altogether; only 20 are illustrated here.

of the cavity output gap to the upstream electrode. After the bricks of a cavity are triggered, parasitic current flows along the inner surfaces of the cavity walls as illustrated by the red arrows of Fig. 2. The arrows represent a parasitic load that is in parallel with the cavity output gap.

The current that follows the path illustrated by the red arrows of Fig. 2 creates a magnetic field within the cavity that diffuses into the ferromagnetic cores and changes their magnetization state. Hence energy is lost to the cores through magnetic-energy diffusion and Ohmic heating. Since the cores absorb energy from the parasitic current, the cores introduce an effective resistance (i.e., $R_{\text {cores }}$ ) in the path of this current, which reduces the magnitude of the current.

In a well-designed cavity, the cores increase substantially the effective resistance of the path indicated by the red arrows of Fig. 2. For such a cavity, the dominant contribution to the resistance of this path is that due to the cores, $R_{\text {cores }}$. The cores of such a cavity reduce substantially the parasitic current, and cause most of the current generated by the bricks within the cavity to be delivered to the cavity output gap. Current delivered to the gap is used to drive the centrally located transmission line of the LTD module [1-20]. 


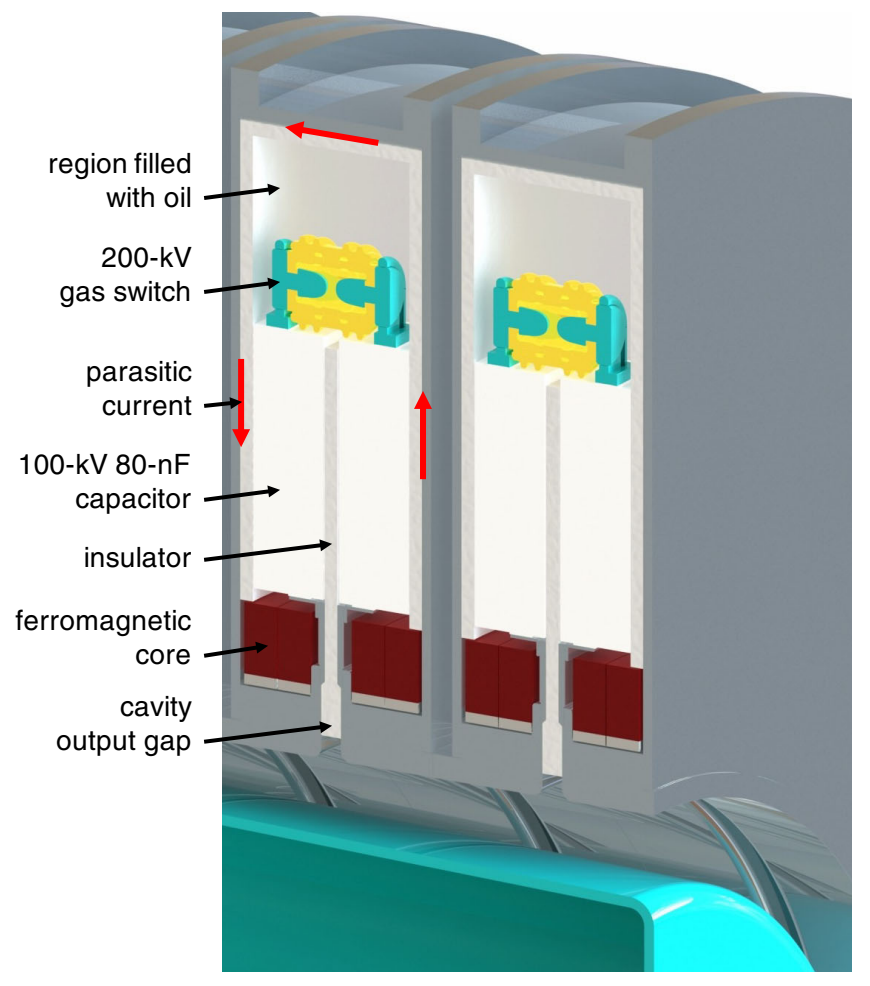

FIG. 2. Cross-sectional view of two LTD cavities. The red arrows indicate the path of parasitic current that flows along the inner surfaces of the walls of each cavity. This current creates a magnetic field within each cavity that diffuses into the ferromagnetic cores and changes their magnetization state. Hence energy is lost to the cores through magnetic-energy diffusion and Ohmic heating. Since the cores absorb energy from the parasitic current, the cores introduce an effective resistance in the path of this current, which reduces its magnitude.

However, the cores also increase the cost and weight of an LTD module. In addition, the magnetization state of the cores within a module must be reset before each module shot to maximize the available volt-second product of the cores at the beginning of the shot. Hence the cores require a core-reset pulse generator that presents an additional cost.

Furthermore, the cores and associated reset circuitry increase cavity-design and operational complexities. Moreover, even the most advanced cores do not create an effectively infinite resistance, and allow a small fraction of the current generated by the bricks within a cavity to be lost by flowing parasitically along the cavity's inner surfaces. An additional issue may be associated with building a petawattclass LTD-powered accelerator: such a machine is likely to require at least $\sim 12,000$ cores $[6,18-20]$, which may be challenging to fabricate in a timely manner.

Motivated by these observations, we have conceived a new class of prime-power sources that do not use ferromagnetic cores: impedance-matched Marx generators (IMGs) [18,20,22-27]. An IMG comprises a single stage or several stages distributed axially and connected electrically in series. Each stage is powered by a single brick or several bricks distributed azimuthally within the stage and connected electrically in parallel. The stages of a multistage IMG drive an impedance-matched coaxial transmission line with a conical center conductor.

The bricks that power an IMG can be designed to generate an electrical-power pulse with the temporal width required to drive experiments of interest. Hence an IMG can provide single-stage electrical-pulse compression, which eliminates the need for additional stages of pulsecompression hardware. Such hardware can increase design, simulation, engineering, fabrication, and operational complexities, and reduce the energy efficiency of an accelerator. In addition, an IMG is-by definition-impedance matched to a load. Impedance matching maximizes the peak electrical power that is delivered by an IMG to its load, and enables an IMG to achieve a maximum energy efficiency of $\sim 90 \%$. Single-stage pulse compression and impedance matching establish IMGs as attractive primepower sources for pulsed-power accelerators.

An LTD module can also be designed to provide single-stage pulse compression and impedance matching [1-20]. However, for a given electrical-power-output time history, an IMG is less expensive and slightly more efficient than an LTD, since an IMG does not use ferromagnetic cores.

To illustrate the IMG approach to prime power, we have developed conceptual designs of two ten-stage IMGs with $L C$ time constants on the order of $100 \mathrm{~ns}$. One design assumes use of $100-\mathrm{kV} 80-\mathrm{nF}$ capacitors, and delivers a peak electrical power of $1.05 \mathrm{TW}$ to a matched-impedance $1.22-\Omega$ load. The design is outlined by Sec. II. An idealized circuit model of the design is presented by Sec. III; results of circuit simulations are summarized by Sec. IV. The other design assumes 100-kV 160-nF capacitors, and delivers $68 \mathrm{GW}$ to a matched-impedance $19-\Omega$ load. This configuration is outlined by Sec. V; an associated circuit model and circuit-simulation results are presented by Secs. VI and VII, respectively.

We caution that Secs. II-VII describe only conceptual IMG designs. The present article does not describe engineering designs. Describing such designs would require developing engineering designs for the capacitor-charge circuits, capacitor-charge cables, capacitor-charge resistors, switch-trigger pulse generators, switch-trigger cables, switch-trigger circuits, postpulse energy diverters, plastic insulators that provide mechanical support for the IMG's components, plastic insulators that contain the IMG's liquid insulators, oil-handling-and-processing systems, waterhanding-and-processing systems, various diagnostics, etc. Engineering designs have been developed for previous Marx generators, such as the 20-MJ 6-MV Marx-generator system that powers the 85-TW 26-MA Z accelerator at Sandia National Laboratories. However, developing such designs for the two IMG concepts outlined herein would be outside the scope of the present article. 


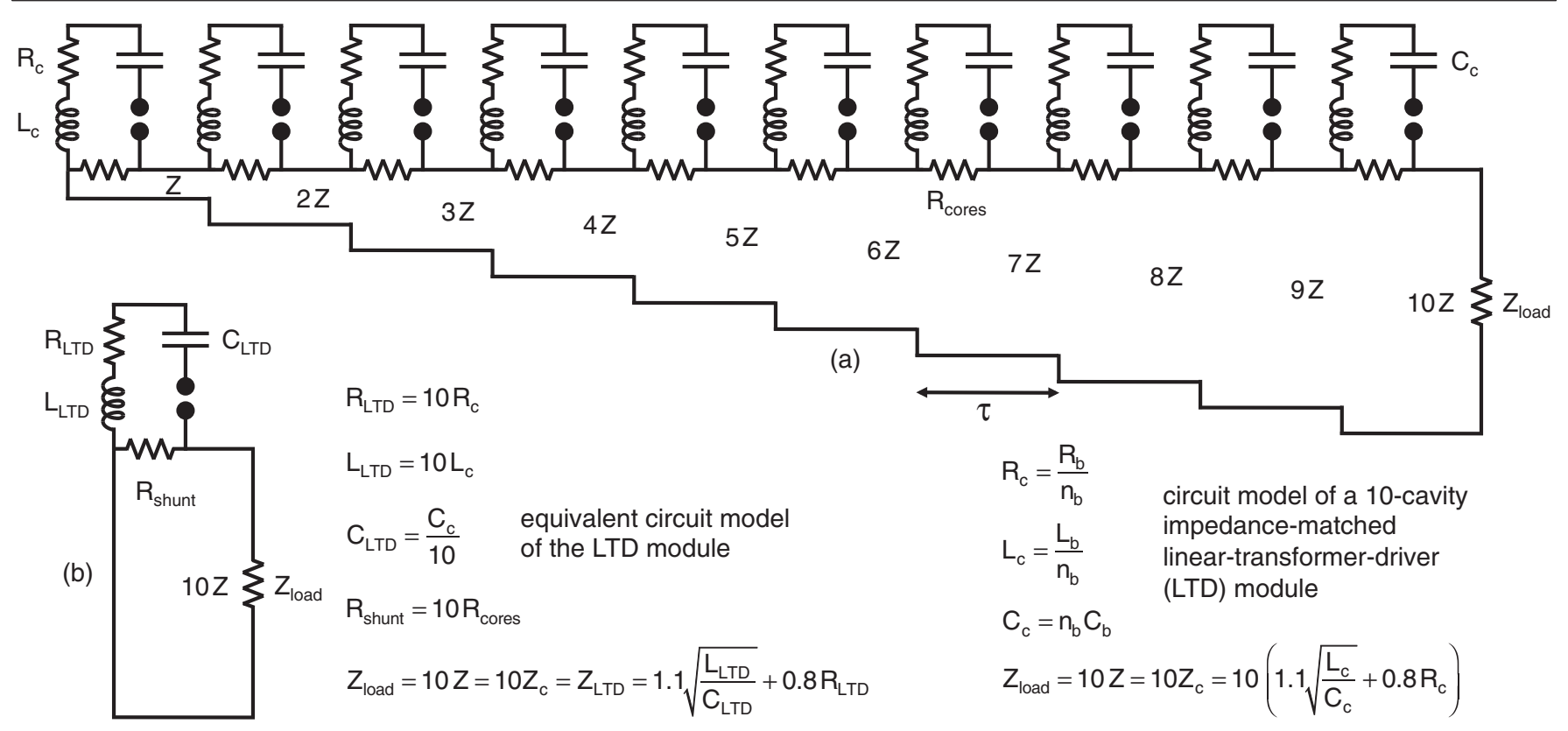

FIG. 3. (a) Circuit model of a ten-cavity LTD module. The module drives a ten-segment impedance-matched transmission line that in turn drives an impedance-matched load. The quantity $R_{c}$ is the effective series resistance of a single LTD cavity, $L_{c}$ is the effective series cavity inductance, $C_{c}$ is the series cavity capacitance, $R_{\text {cores }}$ is the effective parallel resistance within a single cavity due to its ferromagnetic cores, $Z$ is the impedance of the first transmission-line segment, $Z_{\text {load }}$ is the load impedance, $\tau$ is the one-way electromagnetic transit time of a single segment, $R_{b}$ is the effective series resistance of a single brick, $n_{b}$ is the number of bricks per cavity, $L_{b}$ is the effective series brick inductance, and $C_{b}$ is the series brick capacitance. The quantity $Z_{c}$ is the effective impedance of a single cavity; the expression given by the figure for $Z_{c}$ is valid when $R_{\text {cores }} \gg\left[1.1\left(L_{c} / C_{c}\right)^{1 / 2}+0.8 R_{c}\right]$ [7]. (b) When each cavity is triggered at time $\tau$ after the cavity immediately upstream is triggered, the circuit of (a) can be simplified as that given by (b). The quantity $R_{\mathrm{LTD}}$ is the effective series resistance of the LTD module, $L_{\mathrm{LTD}}$ is the effective series module inductance, $C_{\mathrm{LTD}}$ is the series module capacitance, and $R_{\text {shunt }}$ is the effective shunt resistance of the module due to its cores. The quantity $Z_{\mathrm{LTD}}$ is the effective impedance of the ten-cavity LTD module; the expression given by the figure for $Z_{\mathrm{LTD}}$ is valid when $R_{\text {shunt }} \gg\left[1.1\left(L_{\mathrm{LTD}} / C_{\mathrm{LTD}}\right)^{1 / 2}+0.8 R_{\mathrm{LTD}}\right][7]$. When circuit (b) is applicable and the values of $Z$ and $Z_{\text {load }}$ are as given by the figure, the LTD module is impedance matched to the load; i.e., the peak electrical power delivered by the module to the load is maximized.

As observed by Sec. VIII, the simplest form of an IMG is a single brick that drives an impedance-matched load. Such IMGs have already been developed and serve as the prime-power source of the new Thor accelerator [18,20, 22-25,27]. (The first Thor machine has been designed and is being assembled at Sandia.) As suggested by Sec. VIII, IMGs could also be developed to drive a wide variety of other pulsed-power accelerators, such as the Neptune machine [18,20,23,26,27] and possibly Z 300 and Z 800 [18-20].

The Appendix demonstrates analytically that all the reflected and backward voltages within a generalized multistage IMG cancel. Numbered equations in this article are in SI units throughout.

\section{CONCEPTUAL DESIGN OF A 1.05-TW IMG}

A conceptual design of a 1.05-TW impedance-matched Marx generator with an $L C$ time constant of $80 \mathrm{~ns}$ is illustrated by Fig. 4. The IMG consists of ten stages that are distributed axially and connected electrically in series. Each stage is powered by 20 bricks distributed azimuthally within the stage and connected electrically in parallel. Hence the IMG is powered by 200 bricks altogether. (Only 20 of the 200 bricks are illustrated by Fig. 4.)

Each of the 200 bricks is identical to every other brick. Each brick includes two 100-kV 80-nF capacitors connected electrically in series with a single (normally open) 200-kV field-distortion gas switch [28]. Before an IMG shot, the capacitors are dc charged in a balanced manner, so that $+100 \mathrm{kV}$ appears across one of the brick's capacitors, $-100 \mathrm{kV}$ across the other, and $200 \mathrm{kV}$ across the brick's switch [29].

The region within which the bricks are located is filled with oil. After the IMG's 400 capacitors are charged to high voltage (and before the switches are triggered), a potential difference of as much as $200 \mathrm{kV}$ appears between any two exposed conductors within the oil-insulated region of the IMG.

To minimize the probability of dielectric failure within the IMG's oil section while the capacitors are charged to high voltage, we tentatively propose that the oil-section design satisfy everywhere the following relation: 


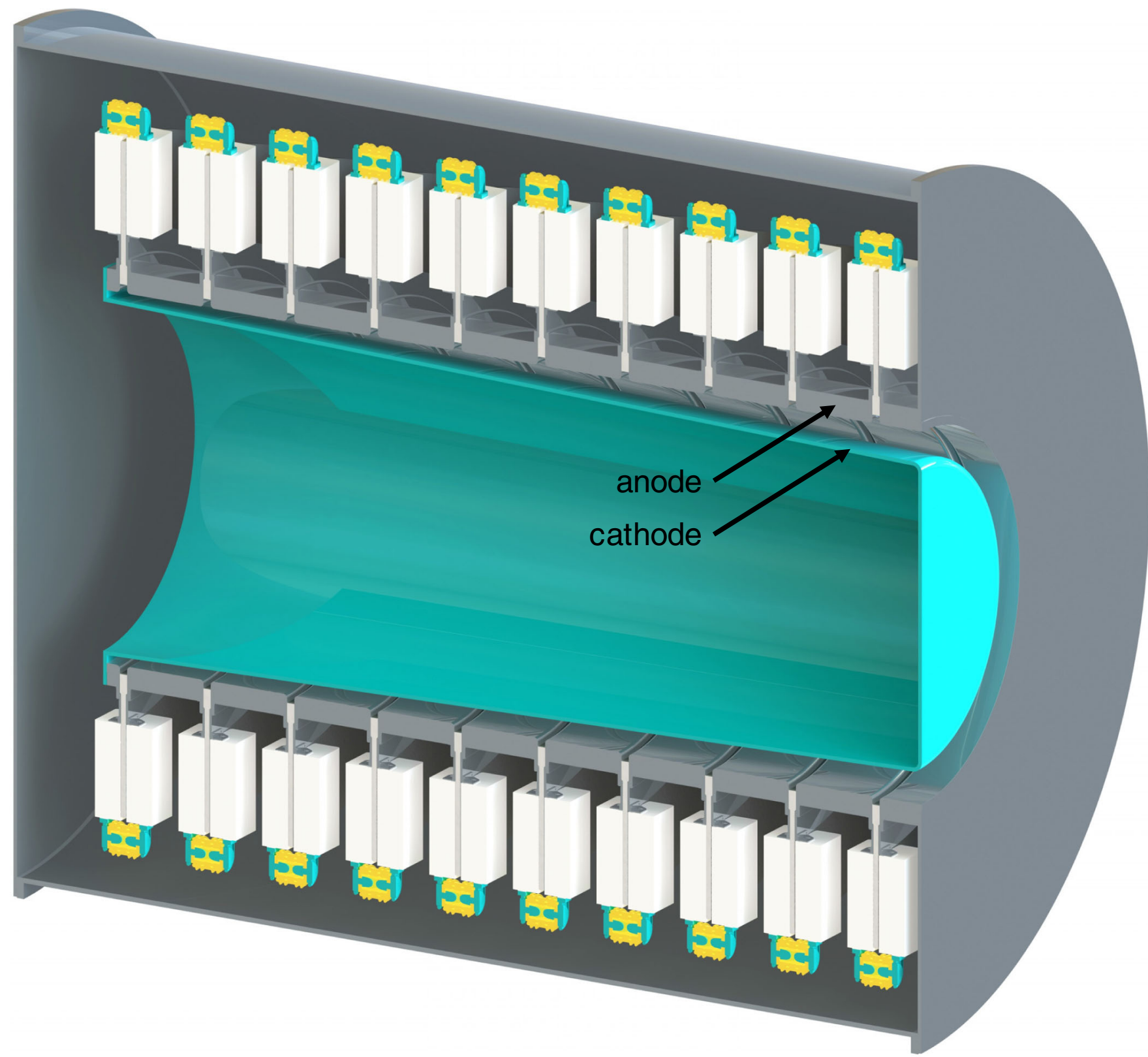

FIG. 4. Cross-sectional view of a ten-stage impedance-matched Marx generator (IMG) with 20 bricks per stage. The IMG is powered by 200 bricks altogether; only 20 are illustrated here.

$$
E_{\text {oil }(\mathrm{dc})} \leq 2 \times 10^{6} \mathrm{~V} / \mathrm{m},
$$

where

$$
E_{\mathrm{oil}(\mathrm{dc})} \equiv \frac{V_{\mathrm{oil}(\mathrm{dc})}}{g_{\mathrm{oil}(\mathrm{dc})}}
$$

The quantity $E_{\text {oil (dc) }}$ is the average dc electric field between two exposed conductors within the oil section, $V_{\text {oil (dc) }}$ is the dc potential difference between the conductors, and $g_{\mathrm{oil}(\mathrm{dc})}$ is the distance between the conductors.
Equation (4), which was determined empirically, assumes that the minimum radius of the exposed electrodes within the IMG oil section is a few millimeters, and the insulating liquid within the section is Shell Diala transformer oil [30] or an equivalent insulator. Equation (4) also assumes the oil is dried, filtered, and degassed by a Parker Sentinel oil-purification system [31] or an equivalent configuration. When the maximum dc potential difference between two conductors is $200 \mathrm{kV}$, Eq. (4) requires that the gap between such conductors be at least $10 \mathrm{~cm}$. As indicated above, we propose Eq. (4) be used for IMG design purposes only on a tentative basis, and suggest 
additional work be conducted to develop definitive IMG-oil-section design criteria for dc voltages.

As indicated by Fig. 4, the ten IMG stages drive an impedance-matched coaxial transmission line located within the IMG. (Impedance matching is achieved as described by Sec. III.) The coaxial line includes a conical center conductor and is water insulated.

While the capacitors are dc charged and before the switches are triggered, no voltage appears across the IMG's coaxial transmission line. After the switches are triggered, a high-voltage pulse propagates along the coaxial line. To minimize the probability of dielectric failure within the coax, its design must satisfy everywhere the following relation $[32,33]$ :

$$
E_{w} \tau_{w}^{0.33} \leq 1.13 \times 10^{5}
$$

where

$$
E_{w} \equiv \frac{V_{w}}{g_{w}} .
$$

At a given location within the coaxial line the quantity $E_{w}$ is the peak value in time of the average electric field between the line's two conductors, $V_{w}$ is the voltage between the conductors, $g_{w}$ is the gap between the conductors, and $\tau_{w}$ is the temporal width of the voltage pulse at $63 \%$ of its peak value $[32,33]$. (Like the other numbered equations in this article, Eq. (6) is in SI units. Different units are used by Refs. [32,33].)

After the IMG switches are triggered, a high-voltage pulse appears not only within the water-insulated coaxial transmission line of the IMG but also the IMG oil section. A potential difference on the order of the peak voltage of the IMG output pulse appears between conductors at the upstream end of the IMG and the IMG's outer enclosure, which is at ground potential.

According to Refs. [34-36], for pulse lengths of interest (i.e., $\sim 100$ ns to $\sim 1 \mu \mathrm{s}$ ), the dielectric strength of oil is a factor of $\sim 2$ greater than that of water. Hence to minimize the probability of dielectric failure within the IMG oil section after the switches are triggered, we tentatively propose that the design of this section satisfy everywhere the same relation used to design the water-insulated coax:

$$
E_{\mathrm{oil}} \tau_{\mathrm{oil}}^{0.33} \leq 1.13 \times 10^{5},
$$

where

$$
E_{\mathrm{oil}} \equiv \frac{V_{\mathrm{oil}}}{g_{\mathrm{oil}}} .
$$

At a given location within the oil section the quantity $E_{\mathrm{oil}}$ is the peak value in time of the average electric field between two exposed conductors, $V_{\text {oil }}$ is the voltage between the conductors, $g_{\mathrm{oil}}$ is the gap between the conductors, and $\tau_{\mathrm{oil}}$ is the temporal width of the voltage pulse at $63 \%$ of its peak value $[32,33]$.

Since Eq. (8) was developed for water, using it to design an oil-insulated region should be conservative [34-36]. As indicated above, we propose that Eq. (8) be used for the oil-insulated section of an IMG on a tentative basis, and suggest additional work be conducted to develop definitive IMG-oil-section design criteria for pulsed voltages.

\section{CIRCUIT MODEL OF THE 1.05-TW IMG}

We have developed an idealized circuit model of the 1.05-TW impedance-matched Marx generator outlined by the previous section. The model was developed using the SCREAMER circuit code [37-39] and is illustrated by Fig. 5 . The circuit elements of the model are discussed in this section.

The circuit model makes the following simplifying assumptions: each of the 200 bricks that drive the IMG are identical to every other brick; each of the IMG's ten stages includes 20 bricks; all the bricks within a stage are triggered simultaneously; and each brick can be modeled as an $R L C$ circuit. Under these conditions the quantities $R_{s}$, $L_{s}$, and $C_{s}$ of Fig. 5 are as follows:

$$
\begin{gathered}
R_{s}=\frac{R_{b}}{n_{b}}, \\
n_{b}=20, \\
L_{s}=\frac{L_{b}}{n_{b}}, \\
C_{s}=n_{b} C_{b} .
\end{gathered}
$$

The quantity $R_{s}$ is the effective series resistance of a single IMG stage, $R_{b}$ is the effective series resistance of a single brick, $n_{b}$ is the number of bricks within each stage, $L_{s}$ is the effective series inductance of a stage, $L_{b}$ is the effective series inductance of a brick, $C_{s}$ is the series capacitance of a stage, and $C_{b}$ is the series capacitance of a brick.

We make the following additional assumptions:

$$
\begin{gathered}
R_{b}=0.3 \Omega, \\
L_{b}=160 \mathrm{nH} .
\end{gathered}
$$

The brick resistance and inductance, $R_{b}$ and $L_{b}$ respectively, are functions of the spatially dependent electron, ion, and neutral-particle temperatures and densities of the current-carrying plasma channels within the brick's switch. Hence the resistance and inductance must be time dependent. Over the time interval of interest, the performance of a brick can be approximated with reasonable accuracy by using effective constant values for these quantities. Equations (14) and (15) give the assumed effective values. 


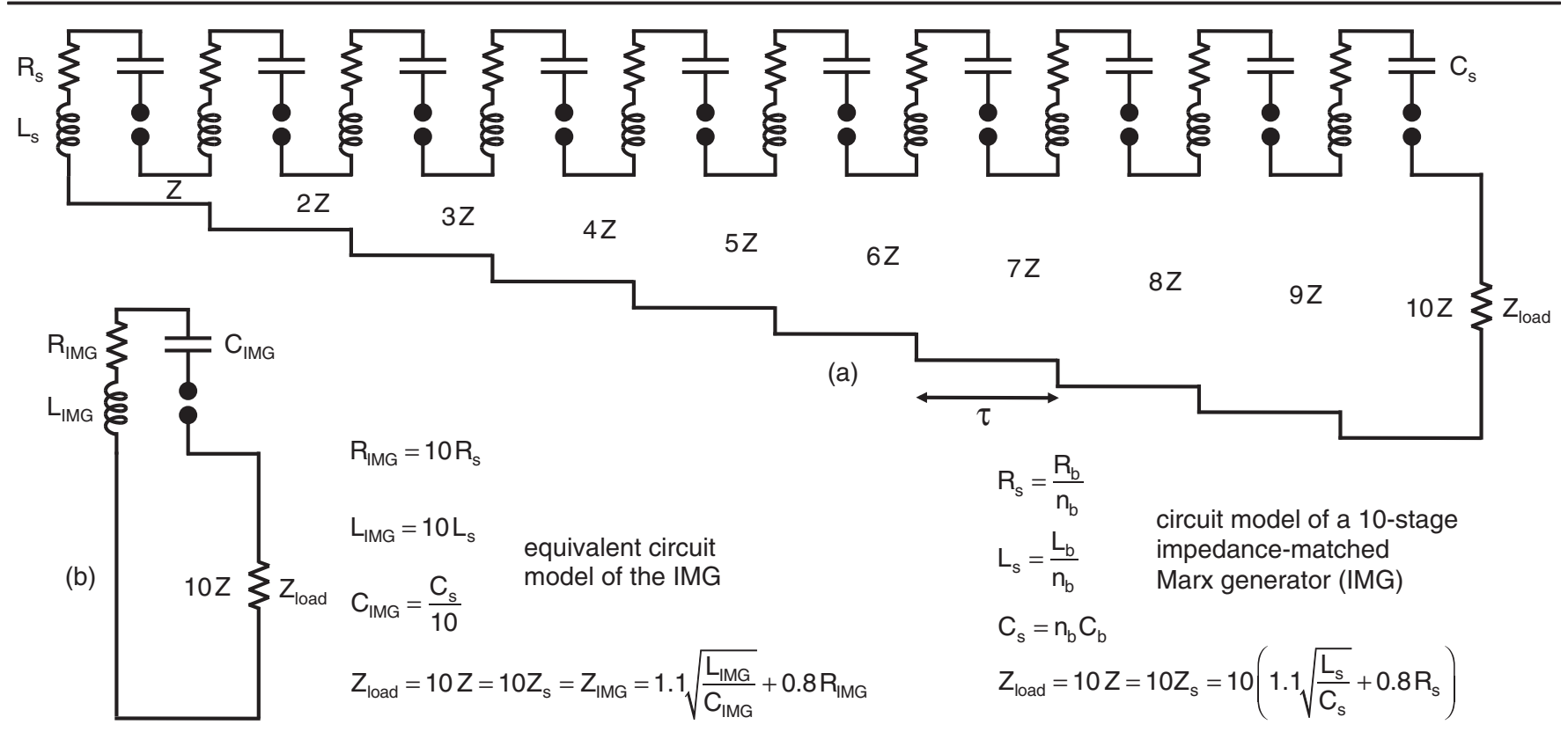

FIG. 5. (a) Circuit model of a ten-stage IMG. The IMG drives a ten-segment impedance-matched transmission line that in turn drives an impedance-matched load. The quantity $R_{s}$ is the effective series resistance of a single IMG stage, $L_{s}$ is the effective series stage inductance, $C_{s}$ is the series stage capacitance, $Z$ is the impedance of the first transmission-line segment, $Z_{\text {load }}$ is the load impedance, $\tau$ is the one-way electromagnetic transit time of a single segment, $R_{b}$ is the effective series resistance of a single brick, $n_{b}$ is the number of bricks per stage, $L_{b}$ is the effective series brick inductance, $C_{b}$ is the series brick capacitance, and $Z_{s}$ is the effective impedance of a single stage. (b) When each stage is triggered at time $\tau$ after the stage immediately upstream is triggered, the circuit of (a) can be simplified as that given by (b). The quantity $R_{\mathrm{IMG}}$ is the effective series resistance of the IMG, $L_{\mathrm{IMG}}$ is the effective series IMG inductance, $C_{\mathrm{IMG}}$ is the series IMG capacitance, and $Z_{\mathrm{IMG}}$ is the effective impedance of the ten-stage IMG. When circuit (b) is applicable and the values of $Z$ and $Z_{\text {load }}$ are as given by the figure, the IMG is impedance matched to the load; i.e., the peak electrical power delivered by the IMG to the load is maximized.

We also assume each brick consists of a single switch that is connected electrically in series with two 80-nF capacitors:

$$
C_{b}=40 \mathrm{nF} \text {. }
$$

Figure 5(a) models the coaxial line that is driven by the IMG as ten transmission-line segments. This figure assumes that the impedance of the $n$th segment is $n Z$, where $Z$ is the impedance of the first segment. The transmission line drives a load with impedance $Z_{\text {load }}$. We make the simplifying assumptions that the transmissionline segments are lossless, the impedance of each section is nonreactive and constant throughout its length, and the load impedance is purely resistive (i.e., nonreactive).

The quantity $\tau$ is the one-way electromagnetic transit time of a single transmission-line segment. As suggested by Figs. 4 and 5, the minimum value of $\tau$ is determined by the geometric distance that is required between bricks. Of course, it is desired to minimize $\tau$ to minimize the total length of the IMG (and hence, the size of the accelerator). Each IMG stage could be command triggered, as is done for an LTD module. (It may be possible to achieve requisite performance of an IMG by command triggering the first few stages of the IMG, then allowing the remaining stages to self-trigger, as is done for a conventional Marx generator.
It is clear such an approach would be more likely to succeed when the number of bricks per stage is small.) When each stage is triggered at time $\tau$ after the stage immediately upstream is triggered, the circuit of Fig. 5(a) can be simplified as Fig. 5(b).

When the circuit model of Fig. 5(b) is applicable, the peak value of the electrical power delivered by the IMG to a load with impedance $Z_{\text {load }}$ is maximized when $Z$ and $Z_{\text {load }}$ satisfy the following relations $[6,7]$ :

$$
\begin{gathered}
Z=Z_{s}=1.1 \sqrt{\frac{L_{s}}{C_{s}}}+0.8 R_{s}, \\
Z_{\mathrm{load}}=n_{s} Z_{s}=Z_{\mathrm{IMG}}=1.1 \sqrt{\frac{L_{\mathrm{IMG}}}{C_{\mathrm{IMG}}}}+0.8 R_{\mathrm{IMG}}, \\
n_{s}=10 \\
L_{\mathrm{IMG}}=n_{s} L_{s} \\
C_{\mathrm{IMG}}=\frac{C_{s}}{n_{s}} \\
R_{\mathrm{IMG}}=n_{s} R_{s} .
\end{gathered}
$$


The quantity $Z_{s}$ is the effective impedance of a single IMG stage, $n_{s}$ is the number of IMG stages, $Z_{\mathrm{IMG}}$ is the effective impedance of the multistage IMG, $L_{\mathrm{IMG}}$ is the effective series inductance of the IMG, $C_{\mathrm{IMG}}$ is the series IMG capacitance, and $R_{\mathrm{IMG}}$ is the effective series IMG resistance.

When the circuit model of Fig. 5(b) is applicable and Eqs. (17)-(22) are satisfied, the IMG is impedance matched to its load; i.e., the peak electrical power delivered by the IMG to the load is maximized. (We do not address here the pulse-shaping technique of Ref. [7].) The expressions given for $Z_{s}$ and $Z_{\mathrm{IMG}}$ by Eqs. (17) and (18) achieve a peak power at the load that is within $1 \%$ of its maximum possible value. It is clear from the above equations that

$$
Z_{\text {load }}=Z_{\mathrm{IMG}}=1.22 \Omega \text {. }
$$

The initial dc charge voltage across an IMG, $V_{\mathrm{IMG}}$, is as follows:

$$
\begin{gathered}
V_{\mathrm{IMG}}=n_{s} V_{s}, \\
V_{s}=V_{b}, \\
V_{b}=200 \mathrm{kV},
\end{gathered}
$$

where $V_{s}$ is the initial dc voltage across a single IMG stage, and $V_{b}$ is the initial de voltage across a single brick.

The total energy initially stored by an IMG, $E_{\mathrm{IMG}}$, is one measure of its size:

$$
\begin{gathered}
E_{\mathrm{IMG}}=\frac{1}{2} C_{\mathrm{IMG}} V_{\mathrm{IMG}}^{2}=\frac{1}{2} n_{\mathrm{IMG}} C_{b} V_{b}^{2}, \\
n_{\mathrm{IMG}}=n_{b} n_{s},
\end{gathered}
$$

where $n_{\mathrm{IMG}}$ is the total number of bricks that power the IMG. According to the above equations, the initial energy stored by the 1.05-TW impedance-matched Marx is $160 \mathrm{~kJ}$.

We define the energy efficiency of a coupled IMG-load system to be the ratio of the energy delivered by the IMG to its load, to the total energy initially stored by the IMG capacitors. Since the energy delivered to a resistive load increases with time during an IMG power pulse, the energy efficiency also increases with time. When the circuit model given by Fig. 5(b) is applicable, the theoretical maximum energy efficiency of an IMG is readily calculated:

$$
\eta_{\max }=\frac{Z_{\mathrm{load}}}{Z_{\mathrm{load}}+R_{\mathrm{IMG}}} .
$$

This is the efficiency that is achieved when the only parasitic resistance within an IMG is $R_{\mathrm{IMG}}$ [which is the case for the idealized circuit model of Fig. 5(b)], and the energy delivered to the load has reached its maximum value. For the IMG outlined by this section and Sec. II,

$$
\eta_{\max }=89 \% \text {. }
$$

\section{RESULTS OF CIRCUIT SIMULATIONS OF THE 1.05-TW IMG}

Results of simulations conducted with the circuit model outlined by Sec. III are summarized in this section. As suggested by Fig. 5, the simulations assume the ten-stage IMG outlined by Secs. II and III drives a ten-segment impedance-matched transmission line; i.e., a transmission line with a spatial impedance profile that is matched to that of the IMG. The simulations assume also that the transmission line in turn drives a matched-impedance load. As discussed by the previous section, such impedance matching maximizes the peak electrical power delivered by the IMG to its load.

Assuming the circuit parameters given by Sec. III, the simulated time histories of the voltage and electrical power at the outputs of the ten transmission-line segments are as plotted by Figs. 6 and 7, respectively.

Before any of the switches of an IMG are triggered, all the bricks within the IMG are dc charged to high voltage. Since each brick is an $R L C$ circuit, and the bricks within each IMG stage are connected electrically in parallel, we can consider each stage - after it is charged and before it is triggered - to be an oscillator in an excited state.

As indicated by Figs. 4 and 5, the stages of an IMG are connected electrically in series. Each stage is triggered by triggering simultaneously all the switches within the stage. When the stages are triggered sequentially as discussed by

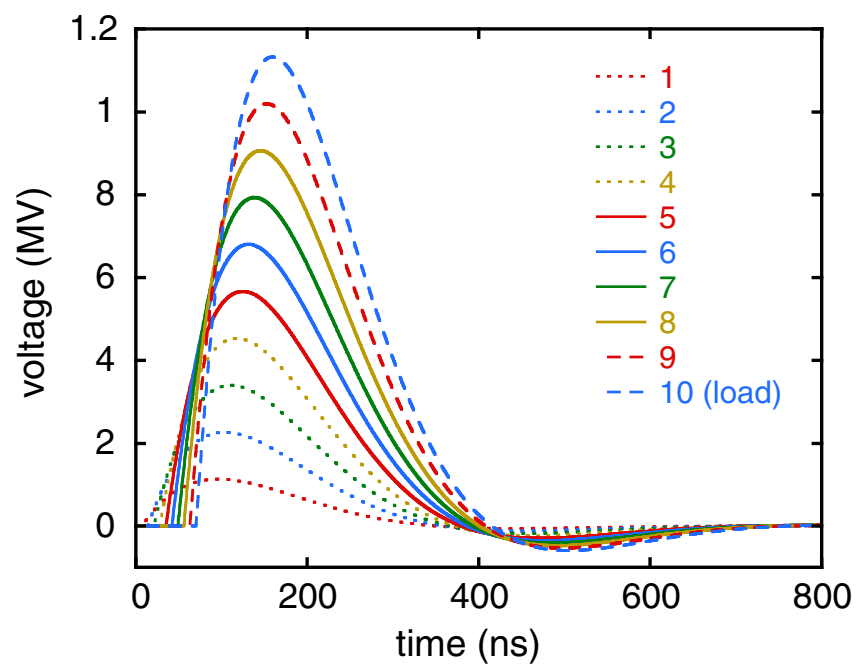

FIG. 6. Simulated voltage time histories at the outputs of the ten transmission-line segments of the ten-stage IMG illustrated by Fig. 4, as given by the circuit model of Fig. 5(a). Since $10 Z=Z_{\text {load }}$, the voltage at the output of the tenth stage is identical to that at the load. 


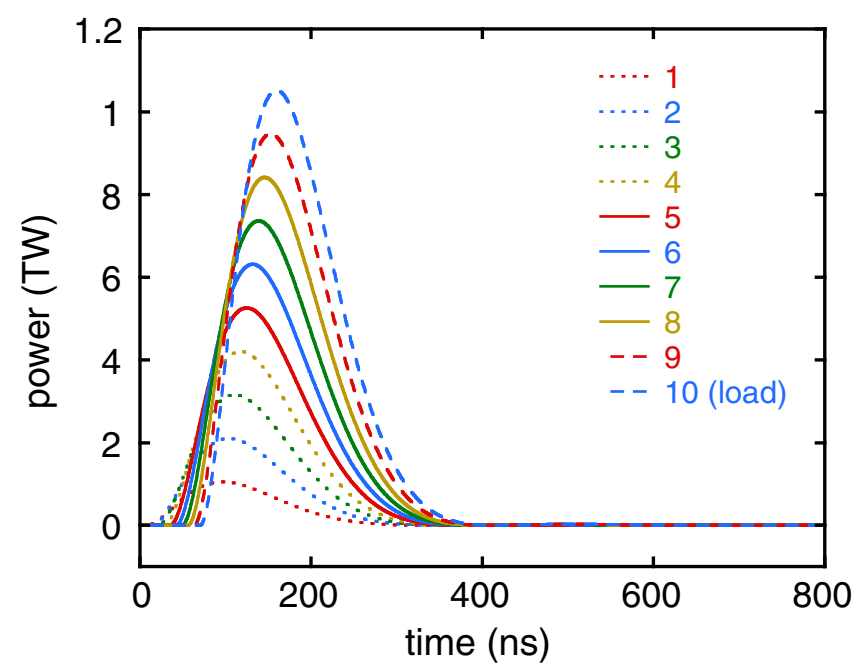

FIG. 7. Simulated electrical-power time histories at the outputs of the ten transmission-line segments of the ten-stage IMG illustrated by Fig. 4, as given by the circuit model of Fig. 5(a). Since $10 Z=Z_{\text {load }}$, the power at the output of the tenth stage is identical to that at the load.

Sec. III, a coherent traveling wave propagates downstream the impedance-matched transmission line of the IMG. The propagation is illustrated by Figs. 6 and 7. The voltage and electromagnetic power of the wave increase with distance along the length of the transmission line, as indicated by these figures.

As indicated by Figs. 6 and 7, the peak voltage and power at the output of an IMG's transmission line are $n_{s} V_{s}$ and $n_{s} P_{s}$, respectively, where $V_{s}$ and $P_{s}$ are the peak voltage and power at the output of the IMG's first transmission-line segment. Hence an IMG achieves power amplification by triggered emission of radiation, and can be considered as a pulsed-power analogue of a laser, with a gain of $n_{s}$. (Since an LTD module operates in a similar manner, such a module can also be considered as a pulsedpower analogue of a laser.)

It is clear that transmitted, reflected, and backward voltages are launched within an IMG's transmission line (when the IMG includes more than a single stage). As demonstrated by the Appendix, the reflected and backward voltages cancel, which immensely simplifies analytic models of an IMG. The cancellation of reflected and backward voltages makes it possible to model an entire IMG as Fig. 5(b); i.e., a single simple $R L C$ circuit. (As suggested by Fig. 3 and the Appendix, these observations also apply to an LTD module.)

Since the reflected and backward voltages cancel, the electrical-power time history delivered by an IMG to a load with impedance $Z_{\mathrm{IMG}}$ is simply a factor of $n_{s}$ greater than the power that would be delivered by one of the IMG's stages to a load with impedance $Z_{s}$. (A single stage would be impedance matched to a load with impedance $Z_{s}$; i.e., the peak electrical power delivered by a stage to a load would be maximized when the impedance of the load

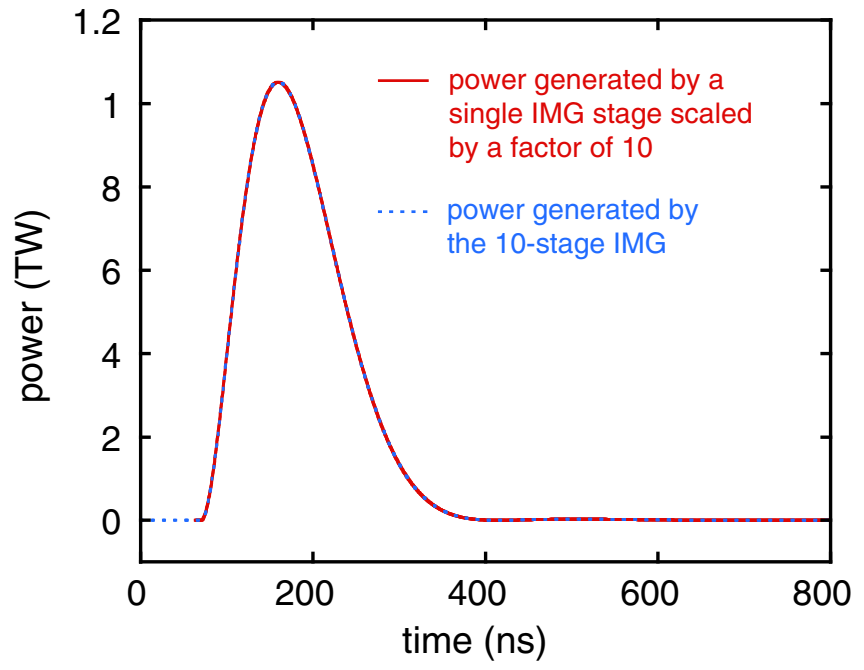

FIG. 8. Simulated electrical-power time histories generated by one of the stages of the IMG illustrated by Fig. 4, and the tenstage IMG. The power generated by a single stage is that which would be delivered by the stage to a matched-impedance load; i.e., a load with impedance $Z_{s}$. The power generated by the tenstage IMG is that which would be delivered by the IMG to a matched-impedance load; i.e., a load with impedance $Z_{\mathrm{IMG}}$.

is $Z_{s}[6,7]$.) For example, as indicated by Fig. 8, the peak power delivered by the ten-stage IMG outlined by Secs. II and III to a matched-impedance $1.22-\Omega$ load is $1.05 \mathrm{TW}$. Hence the peak power that would be delivered by one of the IMG's stages to a matched-impedance $0.122-\Omega$ load is $105 \mathrm{GW}$.

Similarly, when Fig. 5(b) is applicable, the electricalpower time history delivered by an IMG to a load with impedance $Z_{\mathrm{IMG}}$ is simply a factor of $n_{\mathrm{IMG}}$ greater than the power that would be delivered by one of the IMG's bricks to a load with impedance $Z_{b}$, where

$$
Z_{b}=1.1 \sqrt{\frac{L_{b}}{C_{b}}}+0.8 R_{b} .
$$

(A single brick would be impedance matched to a load with impedance $Z_{b}$; i.e., the peak electrical power delivered by a single brick to a load would be maximized when the impedance of the load is $Z_{b}$ [6,7].) For example, as indicated by Fig. 9, the peak power delivered by the 200-brick IMG outlined by Secs. II and III to a matched-impedance $1.22-\Omega$ load is 1.05 TW. Hence the peak power that would be delivered by one of the IMG's bricks to a matched-impedance $2.44-\Omega$ load is $5.25 \mathrm{GW}$.

More generally, when Fig. 5(b) is applicable, the time histories of the voltage, current, power, and energy that are delivered by an IMG to a load with impedance $Z_{\mathrm{IMG}}$ are factors of $n_{s}, 1, n_{s}$, and $n_{s}$, respectively, greater than the time histories that would be delivered by one of the IMG's stages to a load with impedance $Z_{s}$. Similarly, the time histories of the voltage, current, power, and energy 


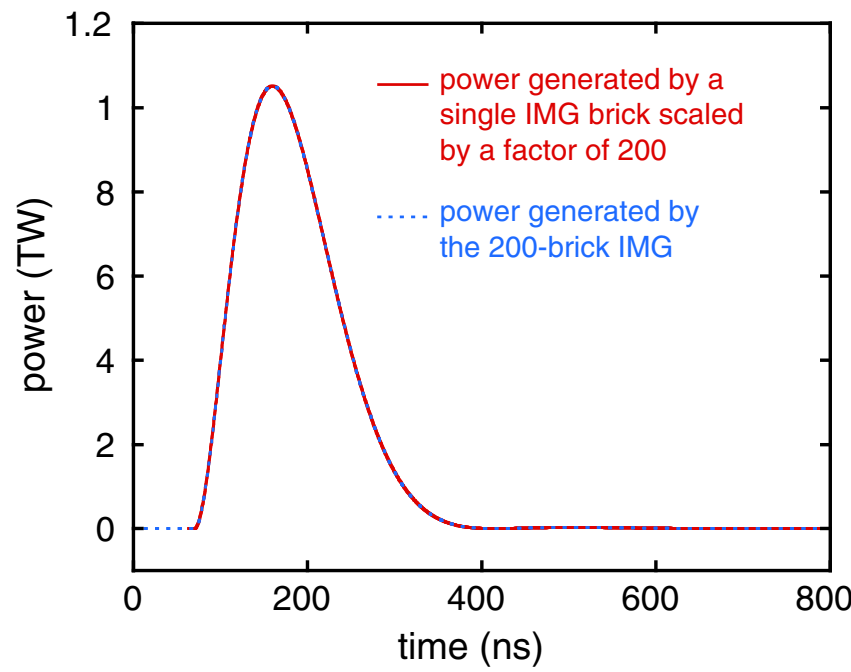

FIG. 9. Simulated electrical-power time histories generated by one of the bricks of the IMG illustrated by Fig. 4, and the 200brick IMG. The power generated by a single brick is that which would be delivered by the brick to a matched-impedance load; i.e., a load with impedance $Z_{b}$. The power generated by the 200brick IMG is that which would be delivered by the IMG to a matched-impedance load; i.e., a load with impedance $Z_{\mathrm{IMG}}$.

delivered by an IMG to a load with impedance $Z_{\mathrm{IMG}}$ are factors of $n_{s}, n_{b}, n_{\mathrm{IMG}}$, and $n_{\mathrm{IMG}}$, respectively, greater than the time histories that would be delivered by one of the IMG's bricks to a load with impedance $Z_{b}$.

When $R_{\mathrm{IMG}} \ll \sqrt{L_{\mathrm{IMG}} / C_{\mathrm{IMG}}}$ and Fig. 5(b) is applicable, we obtain the following additional results:

$$
\begin{gathered}
V_{p}=0.57 n_{s} V_{b}, \\
\tau_{\text {voltage }}=2.2 \sqrt{L_{b} C_{b}}, \\
\tau_{63 \%}=1.8 \sqrt{L_{b} C_{b}}, \\
I_{p}=\frac{V_{p}}{Z_{\text {load }}}, \\
\tau_{\text {current }}=\tau_{\text {voltage }}, \\
P_{p}=0.33 \frac{\left(n_{s} V_{b}\right)^{2}}{Z_{\text {load }}}, \\
\tau_{\text {power }}=1.6 \sqrt{L_{b} C_{b}} .
\end{gathered}
$$

The quantity $V_{p}$ is the peak value of the voltage pulse that is delivered by an IMG to an impedance-matched load, $\tau_{\text {voltage }}$ is the FWHM of the voltage pulse, $\tau_{63 \%}$ is the temporal width of the voltage pulse at $63 \%$ of its peak value, $I_{p}$ is the peak current delivered to the load, $\tau_{\text {current }}$ is the FWHM of the current pulse, $P_{p}$ is the peak power delivered to the load, and $\tau_{\text {power }}$ is the FWHM of the power pulse. Equations (32)-(38) are accurate to within $2 \%$.

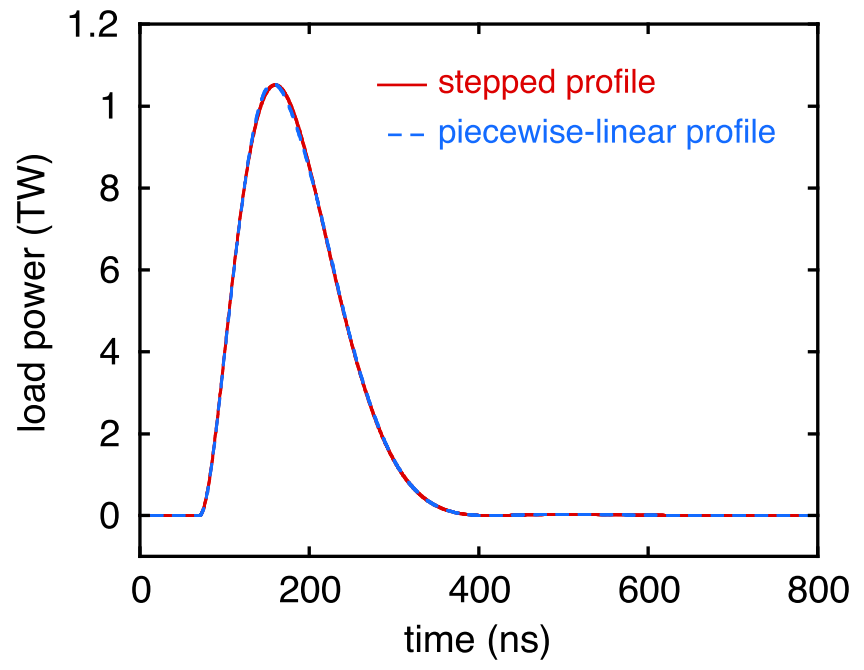

FIG. 10. Simulated electrical-power time histories generated by the ten-stage IMG illustrated by Fig. 4. The red trace assumes the IMG's impedance-matched transmission line has a stepped impedance profile, as suggested by Fig. 5(a). The blue trace assumes a piecewise-linear impedance profile, as suggested by the conical center conductor illustrated by Fig. 4 .

The $L C$ time constant of a single IMG brick can be designed to achieve a pulse with the temporal width required to drive physics experiments of interest. (It is clear that the $L C$ time constant of a single brick is the same as that of a single IMG stage powered by such bricks, and that of an entire IMG powered by such bricks.) Hence an IMG can provide single-stage electrical pulse compression, which eliminates the need for additional stages of pulsecompression hardware.

As indicated by Fig. 6, the peak voltage delivered by the IMG outlined by Secs. II and III to a matched-impedance load is $1.13 \mathrm{MV}$. (The peak voltage generated by each of the ten stages is $113 \mathrm{kV}$.) The temporal width of the load voltage at $63 \%$ of its peak value is $149 \mathrm{~ns}$. Hence according to Eqs. (6) and (8), the peak value of the average electric field between two conductors within the IMG's waterinsulated coaxial transmission line and oil section must not exceed $202 \mathrm{kV} / \mathrm{cm}$.

Figure 5 assumes that the impedance-matched transmission line of a multistage IMG is stepped and consists of constant-impedance segments. However, the center conductor of the transmission line illustrated by Fig. 4 is conical, which provides a smoother impedance profile. Circuit simulations indicate that assuming a piecewiselinear impedance profile instead of one that is stepped has less than a $1 \%$ effect on the output-power time history of an IMG, as demonstrated by Fig. 10.

\section{CONCEPTUAL DESIGN OF A 68-GW IMG}

A conceptual design of a 68-GW IMG with an $L C$ time constant of $126 \mathrm{~ns}$ is illustrated by Fig. 11. The IMG 


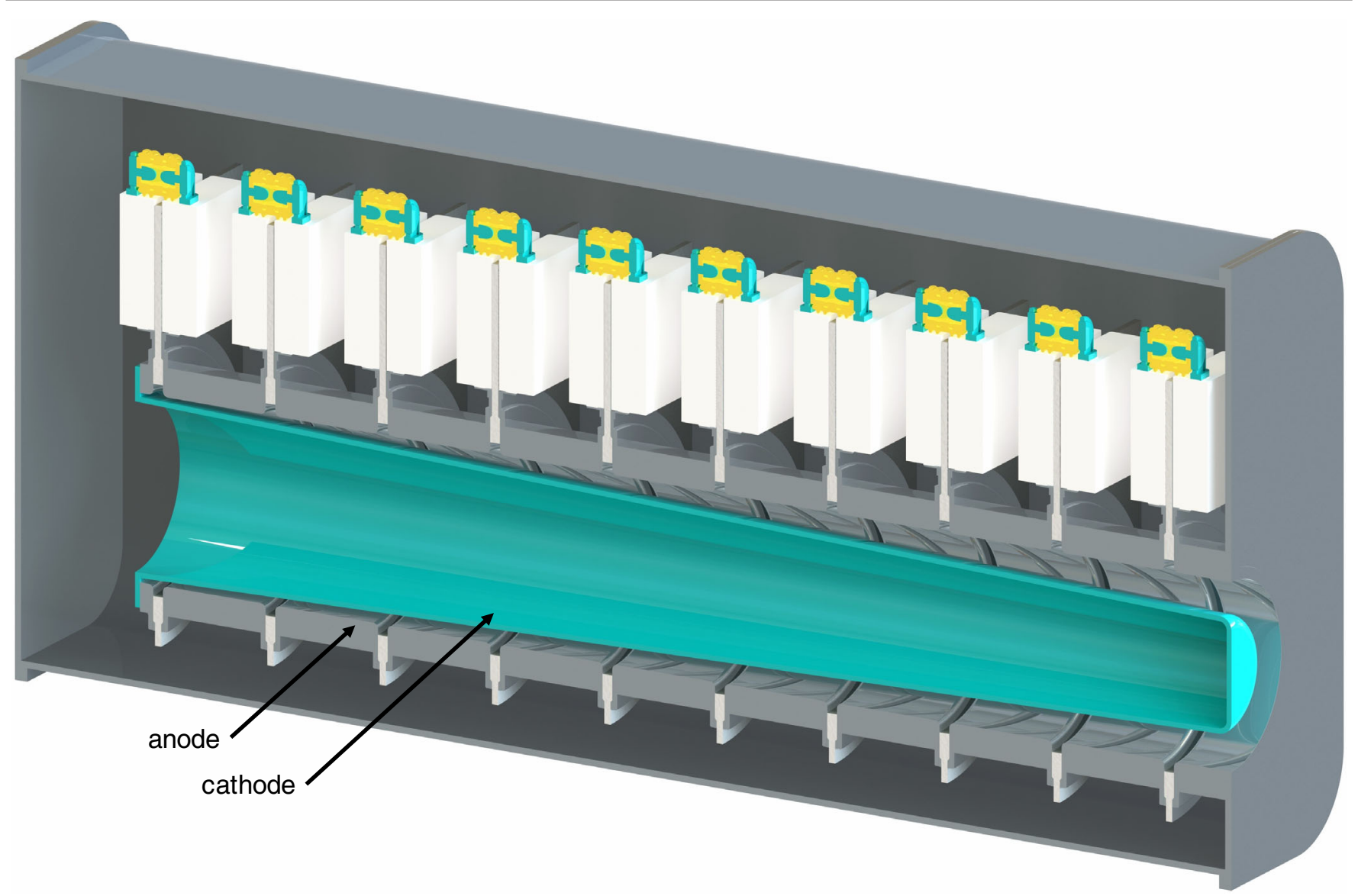

FIG. 11. Cross-sectional view of a ten-stage impedance-matched Marx generator (IMG) with a single brick per stage.

consists of ten stages that are distributed axially and connected electrically in series. Each stage is powered by a single brick; hence the IMG is powered by ten bricks altogether.

Each of the ten bricks is identical to each of the other bricks. We assume each brick consists of two 100-kV $160-\mathrm{nF}$ capacitors connected electrically in series with a single (normally open) 200-kV field-distortion gas switch [28]. Before an IMG shot, the capacitors are dc charged in a balanced manner, so that $+100 \mathrm{kV}$ appears across one of the brick's capacitors, $-100 \mathrm{kV}$ across the other, and $200 \mathrm{kV}$ across the brick's switch [29].

The region within which the bricks are located is filled with and insulated by oil. As indicated by Fig. 11, the ten stages drive an impedance-matched coaxial transmission line. (Impedance matching is achieved as discussed by Sec. III.) The coaxial line includes a conical center conductor. We assume the coaxial line of the 68-GW IMG is oil insulated. (We assume water insulation for the coaxial line of the 1.05TW IMG described by Secs. II-IV since that coax has a substantially lower impedance than that of the 68-GW IMG.)

To minimize the probability of dielectric failure within the IMG's oil section and oil-insulated coaxial transmission line, we tentatively propose that the designs of these components satisfy Eqs. (4) and (8).

\section{CIRCUIT MODEL OF THE 68-GW IMG}

We have developed an idealized circuit model of the $68-G W$ IMG outlined by Sec. V. The model was developed using the SCREAMER circuit code [37-39] and is represented by Fig. 5 .

Figure 5 also represents the 1.05-TW IMG described by Secs. II-IV. Since the 1.05-TW and 68-GW IMG circuit models are similar, we include in this section only equations that differ from those given by Secs. II-IV. For the 68-GW IMG we assume the following:

$$
\begin{gathered}
n_{b}=1, \\
R_{b}=0.2 \Omega, \\
L_{b}=200 \mathrm{nH}, \\
C_{b}=80 \mathrm{nF} .
\end{gathered}
$$

According to Eq. (18) the effective impedance of the IMG is $19 \Omega$ :

$$
Z_{\mathrm{IMG}}=Z_{\mathrm{load}}=19 \Omega \text {. }
$$

According to Eq. (27) the initial energy stored by the IMG is $16 \mathrm{~kJ}$. According to Eq. (29), 


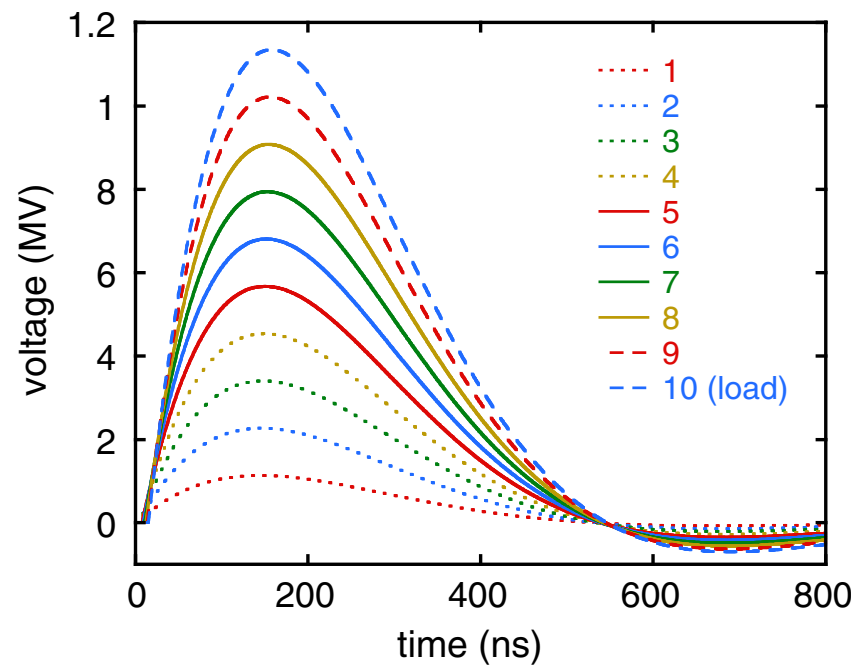

FIG. 12. Simulated voltage time histories at the outputs of the ten transmission-line segments of the ten-stage IMG illustrated by Fig. 11, as given by the circuit model of Fig. 5(a). Since $10 Z=Z_{\text {load }}$, the voltage at the output of the tenth stage is identical to that at the load.

$$
\eta_{\max }=90 \%
$$

\section{RESULTS OF CIRCUIT SIMULATIONS OF THE 68-GW IMG}

Results of simulations conducted with the circuit model outlined by Sec. VI are summarized in this section. Since the circuit models presented by Secs. III and VI are similar, we include in this section only results that differ from those presented in Sec. IV.

Assuming the circuit parameters given by Sec. VI, the simulated time histories of the voltage and power at the

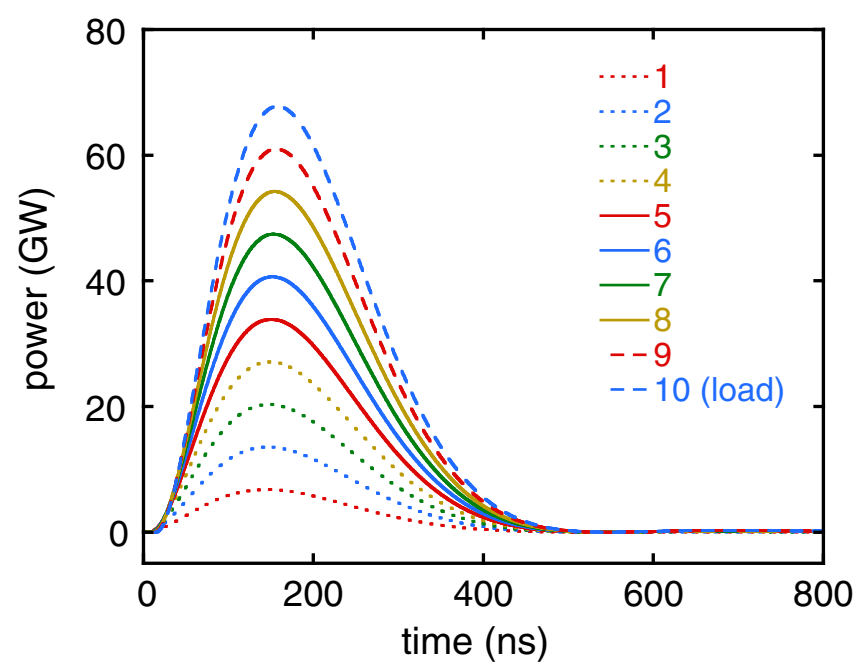

FIG. 13. Simulated electrical-power time histories at the outputs of the ten transmission-line segments of the ten-stage IMG illustrated by Fig. 11, as given by the circuit model of Fig. 5(a). Since $10 Z=Z_{\text {load }}$, the power at the output of the tenth stage is identical to that at the load. outputs of the IMG's ten transmission-line segments are as plotted by Figs. 12 and 13, respectively.

As indicated by Fig. 12, the peak voltage delivered to a matched-impedance load is $1.13 \mathrm{MV}$. (The peak voltage generated by each of the ten stages is $113 \mathrm{kV}$.) The temporal width of the load voltage at $63 \%$ of its peak value is $235 \mathrm{~ns}$. Hence according to Eq. (8), the peak value of the average electric field between two conductors within the IMG's oil section and oil-insulated coaxial transmission line must not exceed $174 \mathrm{kV} / \mathrm{cm}$.

As indicated by Fig. 13, the peak electrical power delivered by the IMG to a matched-impedance load is $68 \mathrm{GW}$. Hence the peak power that would be delivered by each of the IMG's ten bricks to a matched-impedance load is $6.8 \mathrm{GW}$.

\section{DISCUSSION AND SUGGESTIONS FOR FUTURE WORK}

It is clear that the simplest form of an IMG is a single brick that drives an impedance-matched load. Such IMGs have already been developed, and serve as the prime-power source of the new Thor accelerator [18,20,22-25,27]. Presently, each Thor brick drives four polyethyleneinsulated 11- $\Omega$ coaxial transmission lines connected electrically in parallel. The impedance of the set of four parallel lines is approximately matched to that of a single brick. Sandia National Laboratories is presently building a prototype Thor machine that could eventually be driven by as many as 288 bricks [18,20,22-25,27].

IMGs could also be developed to serve as prime power sources for a wide variety of other pulsed-power accelerators, such as the Neptune machine [18,20,23,26,27] and possibly Z 300 and Z 800 [18-20].

The conceptual design of the Neptune accelerator outlined by Refs. [20,26,27] is powered by 600 IMGs. Each IMG consists of eight stages, each of which is driven by a single brick [20,26,27]. The ten-stage IMG described by Secs. V-VII stores twice as much energy as the IMG described by Refs. [20,26,27], and could also be used to power a future Neptune-class accelerator.

The conceptual design of the Z-300 machine outlined by Refs. [18-20] is powered by ninety 33-cavity LTD modules. Each cavity is in turn powered by 20 bricks, each of which has the parameters summarized by Eqs. (10)-(16). We presently assume each Z-300 cavity would contain four ferromagnetic cores; hence Z 300 would use 11,880 cores altogether. In principle, Z 300 could instead be powered by a large number of IMGs, each stage of which would be driven by one or more bricks. Since IMGs do not use ferromagnetic cores, the IMGs would be slightly more efficient than the LTD modules. In addition, eliminating the cores would eliminate potential core-supply-chain issues. However, using IMGs would likely require that the diameter of $\mathrm{Z} 300$ be larger than that estimated by 
Refs. [18-20]. Similarly, the Z-800 accelerator [18-20] could be driven by IMGs instead of LTDs.

The two conceptual IMG designs outlined by this article are intended to serve as a starting point for the development of optimized final designs for next-generation accelerators.

We recommend that an IMG-development effort determine-for a given accelerator-the optimum brick design, number of bricks per stage, number of stages, and IMG design. In addition, we recommend such an effort include the following activities: (1) development of a detailed transmission-line-circuit model of the optimized IMG; (2) development of a 3D electromagnetic model of the IMG; (3) continued development of advanced capacitors, capacitor-charge cables, capacitor-charge resistors, switches, switch-trigger pulse generators, switch-trigger cables, switch-trigger circuits, impedance-matched coaxial transmission lines, liquid insulators, and postpulse energy diverters; (4) design, fabrication, assembly, and commissioning of a full-scale prototype IMG; and (5) demonstration that the prototype IMG meets all safety, electrical, mechanical, diagnostic, reliability, operational, and cost requirements.

\section{ACKNOWLEDGMENTS}

The authors are immensely grateful to the following for invaluable contributions: Tommy Ao, Farhat Beg, John Benage, Mike Campbell, Bob Cooper, Christine Coverdale, Jean-Paul Davis, Joel Ennis, David Fehl, Dawn Flicker, Paul Gard, Ron Gilgenbach, Mark Gilmore, Gary Greiser, Fred Gruner, Tom Haill, Clint Hall, Robert Hohlfelder, Dan Jobe, Peter Jones, Kirk Keilholtz, Mark Kiefer, Josh Leckbee, Ray Leeper, Jane Lehr, Finis Long, John Maenchen, Thomas Mattsson, Keith Matzen, Russ Olson, John Porter, Bill Rhodes, Seth Root, David Sandoval, Ray Scarpetti, Edl Schamiloglu, Ralph Schneider, Bryan Sims, Dan Sinars, Rick Spielman, Eduardo Waisman, Pete Wakeland, and Joe Woodworth. We are also extremely indebted to our many other colleagues at the following organizations for their gracious and sustained scientific support: Sandia National Laboratories, ASR Corporation, Barth Electronics, C-Lec Plastics, Cornell University, CSI Technologies, EG\&G, General Atomics, Idaho State University, Imperial College, Kinetech Corporation, L-3 Communications, Laboratory for Laser Energetics at the University of Rochester, Lawrence Livermore National Laboratory, Los Alamos National Laboratory, National Nuclear Security Administration, National Security Technologies, Naval Research Laboratory, NWL Capacitor Division, Raytheon-Ktech Corporation, Tech Source Consulting, Texas Tech University, University of California at San Diego, University of Michigan at Ann Arbor, University of Missouri at Columbia, University of Nevada at Reno, University of New Mexico, University of Texas at Austin, Voss Scientific, Votaw Precision Technologies, and Weizmann Institute. This work was supported by the National Nuclear Security Administration, and the Laboratory Directed Research and Development Program at Sandia National Laboratories. Sandia is a multiprogram laboratory operated by Sandia Corporation, a Lockheed Martin Company, for the United States Department of Energy's National Nuclear Security Administration under Contract No. DE-AC04-94AL85000.

\section{APPENDIX: DEMONSTRATION THAT THE REFLECTED AND BACKWARD VOLTAGES WITHIN AN IMG CANCEL}

In this Appendix we demonstrate analytically that the reflected and backward voltages within the coaxial transmission line of an IMG cancel. To assist with this demonstration we consider Fig. 14(a), which models an
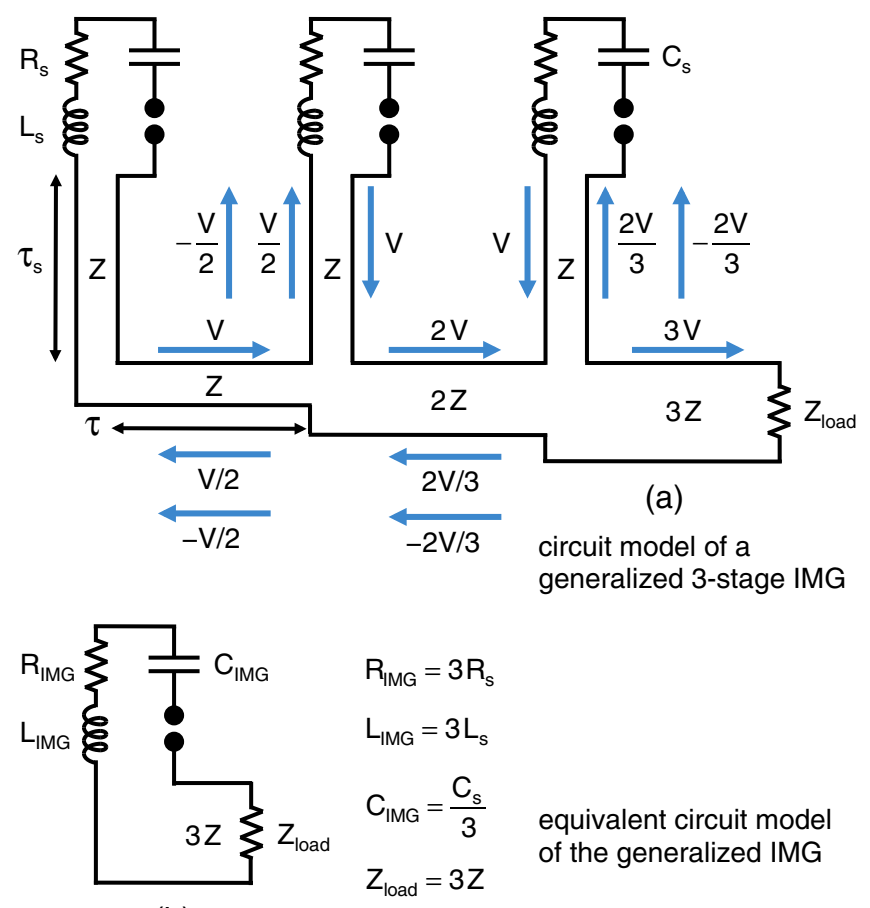

(b)

FIG. 14. (a) Circuit model of a generalized three-stage impedance-matched Marx generator (IMG). The quantity $R_{s}$ is the effective series resistance of a single IMG stage; $L_{s}$ is the effective series stage inductance; $C_{s}$ is the series stage capacitance; $Z$ is the impedance of each of the vertical transmission-line segments driven by the IMG, as well as that of the first horizontal segment; $\tau_{s}$ is the one-way electromagnetic transit time of a vertical segment; $\tau$ is the one-way electromagnetic transit time of a horizontal segment; and $V$ is the time-dependent forward-going voltage that is launched by each stage. (b) When each stage is triggered at time $\tau$ after the stage immediately upstream is triggered, the circuit of (a) can be simplified as that given by (b). The quantity $R_{\mathrm{IMG}}$ is the effective series resistance of the IMG, $L_{\mathrm{IMG}}$ is the effective series IMG inductance, $C_{\mathrm{IMG}}$ is the series IMG capacitance, and $Z_{\text {load }}$ is the load impedance. The figure makes clear that all the reflected and backward voltages within a generalized multistage IMG cancel. 
IMG that is more general than that modeled by Fig. 5 . Figure 14(a) outlines a three-stage generalized IMG; the results presented in this section are valid for a generalized IMG with an arbitrary number of stages.

The transmission-line segments of Fig. 14(a) that are illustrated horizontally represent the IMG's coaxial transmission line. We assume each horizontal transmission-line segment is lossless and has a constant nonreactive impedance. As suggested by Fig. 14(a), the impedance of the $n$th horizontal segment is $n Z$. The one-way transit time of each segment is $\tau$.

Each transmission-line segment of Fig. 14(a) that is illustrated vertically connects an IMG stage to the coaxial transmission line. Figure 14(a) represents each IMG stage as a single $R L C$ circuit. We assume each vertical transmission-line segment is lossless and has a constant nonreactive impedance. The impedance of each of these segments is $Z$; the one-way transit time of each of these segments is $\tau_{s}$. We assume the $R L C$ drive circuit of each stage is identical to that of every other stage, and each stage is triggered at time $\tau$ after the stage immediately upstream is triggered. The quantity $V$ of Fig. 14 is the time-dependent forward-going voltage that is launched by each stage in its associated vertical transmission-line segment.

Under the conditions given above, the well-known analytic voltage transmission and reflection coefficients for an ideal lossless transmission line connected to an ideal nonreactive load can be used to calculate the transmitted, reflected, and backward voltages within the horizontal and vertical transmission-line segments of a generalized IMG.

We first consider the horizontal segments. It is straightforward to demonstrate that the transmitted voltage in the $n$th horizontal segment of a multistage IMG is the sum of the transmitted voltages generated by stages 1 through $n$, and that the sum of these voltages is $n V$ :

transmitted voltage in the $n$th horizontal segment $=n V$.

When the transmitted voltage in the $n$th horizontal segment interacts with the beginning of the $(n+1)$ th horizontal segment, a reflected voltage is generated in the $n$th horizontal segment:

reflected voltage in the $n$th horizontal segment

$$
=\frac{2 n V}{(2 n+2)} \text {. }
$$

The forward-going voltage generated by the $R L C$ circuit of stage $n+1$ propagates downward in the $(n+1)$ th vertical transmission-line segment. When this voltage interacts with the beginning of the $(n+1)$ th horizontal segment, it generates a backward voltage in the $n$th horizontal segment: backward voltage in the $n$th horizontal segment

$$
=\frac{-2 n V}{(2 n+2)} \text {. }
$$

As indicated by Eqs. (A2) and (A3), the reflected and backward voltages in the $n$th horizontal segment cancel. All that is left in the $n$th horizontal segment is the transmitted voltage $n V$.

Let us now consider the vertical transmission-line segments of Fig. 14(a). As mentioned above, the time-dependent forward-going voltage in each vertical segment is $V$. When the forward-going voltage generated by the $R L C$ circuit of the $(n+1)$ th stage interacts with the beginning of the $(n+1)$ th horizontal segment, a reflected voltage is generated in the $(n+1)$ th vertical segment with the following amplitude:

reflected voltage in the $(n+1)$ th vertical segment

$$
=\frac{2 n V}{(2 n+2)} \text {. }
$$

When the transmitted voltage $n V$ in the $n$th horizontal segment interacts with the beginning of the $(n+1)$ th horizontal segment, a backward voltage is generated in the $(n+1)$ th vertical segment with the following amplitude:

backward voltage in the $(n+1)$ th vertical segment

$$
=\frac{-2 n V}{(2 n+2)} \text {. }
$$

As indicated by Eqs. (A4) and (A5), the reflected and backward voltages in the $(n+1)$ th vertical transmissionline segment cancel. All that is left in the $(n+1)$ th vertical segment is the forward-going voltage $V$.

As indicated by Eqs. (A2)-(A5) and Fig. 14(a), all the reflected and backward voltages in the horizontal and vertical segments of a generalized multistage IMG cancel.

One can demonstrate that all the reflected and backward voltages cancel without using Eqs. (A2)-(A5), as follows. The discussion above makes clear that the total timedependent forward-going electrical power launched by stages 1 through $n$ in the first $n$ vertical transmission-line segments of a generalized IMG is $n V^{2} / Z$. According to Eq. (A1), the time-dependent transmitted electrical power in the $n$th horizontal transmission-line segment is $(n V)^{2} / n Z=n V^{2} / Z$. Since these two power time histories are identical, energy conservation requires that all the reflected and backward voltages within a generalized multistage IMG must cancel.

Because all the reflected and backward voltages cancel, the voltage delivered to the load is independent of both $\tau$ and $\tau_{s}$. Hence the voltage delivered to a load by a generalized multistage IMG is identical to that delivered by an IMG with $\tau_{s}=0$; i.e., for the type of IMG illustrated 
by Fig. 5(a). Furthermore, since the load voltage is independent of $\tau$ and $\tau_{s}$, it is clear that the circuit of Fig. 14(a) delivers the same time-dependent voltage to the load as does the circuit of Fig. 14(b), which assumes both $\tau$ and $\tau_{s}$ are equal to 0 .

The results of this Appendix are valid for arbitrary values of $Z$ and $Z_{\text {load }}$ as long as $Z_{\text {load }}=n_{s} Z$. The peak electrical power delivered by a generalized IMG to its load is maximized when $Z_{\mathrm{load}}=\left[1.1\left(L_{\mathrm{IMG}} / C_{\mathrm{IMG}}\right)^{1 / 2}+0.8 R_{\mathrm{IMG}}\right]$; however, the results of this Appendix do not require that $Z_{\text {load }}$ be given by this expression.

We observe that the results of this Appendix are also valid for an LTD module that meets the conditions given above. In addition, the results are consistent with the discussion in Sec. III B 1 of Ref. [40].

[1] B. M. Koval'chuk, V. A. Vizir', A. A. Kim, E. V. Kumpyak, S. V. Loginov, A. N. Bastrikov, V. V. Chervyakov, N. V. Tsoi, P. Monjaux, and D. Kh'yui, Fast primary storage device utilizing a linear pulse transformer, Sov. Izw. Vuzov. Phys. 40, 25 (1997) [Russ. Phys. J. 40, 1142 (1997)].

[2] A. N. Bastrikov, V. A. Vizir, S. N. Volkov, V. G. Durakov, A. M. Efremov, V. B. Zorin, A. A. Kim, B. M. Kovalchuk, E. V. Kumpjak, S. V. Loginov, V. A. Sinebryuhov, N. V. Tsou, V. V. Cervjakov, V. P. Yakovlev, and G. A. Meyats, Primary energy storages based on linear transformer stages, Laser Part. Beams 21, 295 (2003).

[3] C. L. Olson, Z-pinch inertial fusion energy, in LandholtBoernstein Handbook on Energy Technologies, edited by W. Martienssen and K. Heinloth, Fusion Technologies Vol. VIII/3 (Springer-Verlag, Berlin, 2005).

[4] J. J. Leckbee, J. E. Maenchen, D. L. Johnson, S. Portillo, D. M. Van De Valde, D. V. Rose, and B. V. Oliver, Design, simulation, and fault analysis of a 6.5-MV LTD for flash X-ray radiography, IEEE Trans. Plasma Sci. 34, 1888 (2006).

[5] D. V. Rose, D. R. Welch, B. V. Oliver, J. J. Leckbee, J. E. Maenchen, D. L. Johnson, A. A. Kim, B. M. Kovalchuk, and V. A. Sinebryukhov, Numerical analysis of a pulsed compact LTD system for electron beam-driven radiography, IEEE Trans. Plasma Sci. 34, 1879 (2006).

[6] W. A. Stygar, M. E. Cuneo, D. I. Headley, H. C. Ives, R. J. Leeper, M. G. Mazarakis, C. L. Olson, J. L. Porter, T. C. Wagoner, and J. R. Woodworth, Architecture of petawattclass z-pinch accelerators, Phys. Rev. ST Accel. Beams 10, 030401 (2007).

[7] W. A. Stygar, W. E. Fowler, K. R. LeChien, F. W. Long, M. G. Mazarakis, G. R. McKee, J. L. McKenney, J. L. Porter, M. E. Savage, B. S. Stoltzfus, D. M. Van De Valde, and J. R. Woodworth, Shaping the output pulse of a lineartransformer-driver module, Phys. Rev. ST Accel. Beams 12, 030402 (2009).

[8] M. G. Mazarakis, W. E. Fowler, A. A. Kim, V. A. Sinebryukhov, S. T. Rogowski, R. A. Sharpe, D. H. McDaniel, C. L. Olson, J. L. Porter, K. W. Struve, W. A. Stygar, and J. R. Woodworth, High current, 0.5-MA, fast, 100-ns, linear transformer driver experiments, Phys. Rev. ST Accel. Beams 12, 050401 (2009).

[9] A. A. Kim, M. G. Mazarakis, V. A. Sinebryukhov, B. M. Kovalchuk, V. A. Visir, S. N. Volkov, F. Bayol, A. N. Bastrikov, V. G. Durakov, S. V. Frolov, V. M. Alexeenko, D. H. McDaniel, W. E. Fowler, K. LeChien, C. Olson, W. A. Stygar, K. W. Struve, J. Porter, and R. M. Gilgenbach, Development and tests of fast 1-MA linear transformer driver stages, Phys. Rev. ST Accel. Beams 12, 050402 (2009).

[10] J. R. Woodworth, J. A. Alexander, F. R. Gruner, W. A. Stygar, M. J. Harden, J. R. Blickem, G. J. Dension, F. E. White, L. M. Lucero, H. D. Anderson, L. F. Bennett, S. F. Glover, D. Van De Valde, and M. G. Mazarakis, Low-inductance gas switches for linear transformer drivers, Phys. Rev. ST Accel. Beams 12, 060401 (2009).

[11] K. LeChien et al., A 1-MV, 1-MA, 0.1-Hz linear transformer driver utilizing an internal water transmission line, in Proceedings of the 17th IEEE International Pulsed Power Conference (IEEE, Piscataway, NJ, 2009), p. 1186.

[12] M. G. Mazarakis et al., High-current linear transformer driver development at Sandia National Laboratories, IEEE Trans. Plasma Sci. 38, 704 (2010).

[13] A. A. Kim, M. G. Mazarakis, V. I. Manylov, V. A. Vizir, and W. A. Stygar, Energy loss due to eddy current in linear transformer driver cores, Phys. Rev. ST Accel. Beams 13, 070401 (2010).

[14] J. R. Woodworth, W. A. Stygar, L. F. Bennett, M. G. Mazarakis, H. D. Anderson, M. J. Harden, J. R. Blickem, F. R. Gruner, and R. White, New low inductance gas switches for linear transformer drivers, Phys. Rev. ST Accel. Beams 13, 080401 (2010).

[15] D. V. Rose, C. L. Miller, D. R. Welch, R. E. Clark, E. A. Madrid, C. B. Mostrom, W. A. Stygar, K. R. LeChien, M. A. Mazarakis, W. L. Langston, J. L. Porter, and J. R. Woodworth, Circuit models and three-dimensional electromagnetic simulations of a 1-MA linear transformer driver stage, Phys. Rev. ST Accel. Beams 13, 090401 (2010).

[16] J. R. Woodworth, W. E. Fowler, B. S. Stoltzfus, W. A. Stygar, M. E. Sceiford, M. G. Mazarakis, H. D. Anderson, M. J. Harden, J. R. Blickem, R. White, and A. A. Kim, Compact $810 \mathrm{kA}$ linear transformer driver cavity, Phys. Rev. ST Accel. Beams 14, 040401 (2011).

[17] T. C. Genoni, D. V. Rose, R. E. Clark, D. R. Welch, and W. A. Stygar, Efficient ferromagnetic core impedance model with application to finite-difference time-domain simulation, Phys. Rev. ST Accel. Beams 15, 010401 (2012).

[18] W. Stygar et al., Sandia National Laboratories Report No. SAND2015-4846C, 2015.

[19] W. A. Stygar et al., Conceptual designs of two petawattclass pulsed-power accelerators for high-energy-densityphysics experiments, Phys. Rev. ST Accel. Beams 18, 110401 (2015).

[20] W. Stygar et al., Sandia National Laboratories Report No. SAND2016-4276C, 2016.

[21] D. R. Welch, T. C. Genoni, D. V. Rose, N. L. Bruner, and W. A. Stygar, Optimized transmission-line impedance transformers for petawatt-class pulsed-power accelerators, Phys. Rev. ST Accel. Beams 11, 030401 (2008). 
[22] W. Stygar, R. Focia, W. Fowler, B. Hutsel, M. Mazarakis, J. Porter, S. Roznowski, M. Savage, and B. Stoltzfus, Conceptual design of a megabar-class accelerator for material-physics experiments, Fourth Fundamental Science with Pulsed Power Workshop: Research Opportunities and User Meeting (Sandia National Laboratories, Albuquerque, New Mexico, 2012).

[23] B. S. Stoltzfus, K. Austin, B. T. Hutsel, D. Reisman, M. E. Savage, and W. A. Stygar, Variable-pulse-shape pulsedpower accelerator, U.S. Patent Application U.S. 2015/ 0366045 A1 (2015).

[24] D. B. Reisman, B. S. Stoltzfus, W. A. Stygar, K. N. Austin, E. M. Waisman, R. J. Hickman, J.-P. Davis, T. A. Haill, M. D. Knudson, C. T. Seagle, J. L. Brown, D. A. Goerz, R. B. Spielman, J. A. Goldlust, and W. R. Cravey, Pulsed power accelerator for material physics experiments, Phys. Rev. ST Accel. Beams 18, 090401 (2015).

[25] E. M. Waisman, D. B. Reisman, B. S. Stoltzfus, W. A. Stygar, M. E. Cuneo, T. A. Haill, J.-P. Davis, J. L. Brown, C. T. Seagle, and R. B. Spielman, Optimization of current waveform tailoring for magnetically-driven isentropic compression experiments, Rev. Sci. Instrum. 87, 063906 (2016).

[26] W. A. Stygar et al., Conceptual design of a $10^{13}-\mathrm{W}$ pulsed-power accelerator for megajoule-class dynamicmaterial-physics experiments, Phys. Rev. Accel. Beams 19, 070401 (2016).

[27] D. B. Reisman, E. M. Waisman, B. S. Stoltzfus, K. N. Austin, W. A. Stygar, T. Ao, D. V. Morgan, M. E. Cuneo, L. Collier, T. A. Haill, R. J. Hickman, J.-P. Davis, J. L. Brown, C. T. Seagle, T. D. Mulville, E. W. Breden, P. D. Gard, and R. B. Spielman, Sandia National Laboratories Report No. SAND2016-7806 PE, 2016.

[28] F. Gruner, W. Stygar, B. Stoltzfus, J. Woodworth, M. Abdalla, W. Gruner, M. Skipper, and S. Romero, A robust, low-inductance, low-jitter switch for petawatt-class pulsed power accelerators, 19th IEEE International Pulsed Power Conference (IEEE, Piscataway, NJ, 2013).

[29] M. E. Savage, Balanced two-capacitor brick for linear transformer drivers (unpublished).
[30] http://www.shell.com/business-customers/lubricants-for -business/shell-diala-electrical-oils.html.

[31] http://www.parkerhfde.com/pdf/conmon/Sentinel\%200il\% 20Purification\%20System.pdf.

[32] W. A. Stygar, T. C. Wagoner, H. C. Ives, Z. R. Wallace, V. Anaya, J. P. Corley, M. E. Cuneo, H. C. Harjes, J. A. Lott, G. R. Mowrer, E. A. Puetz, T. A. Thompson, S. E. Tripp, J. P. VanDevender, and J. R. Woodworth, Water-dielectricbreakdown relation for the design of large-area multimegavolt pulsed-power systems, Phys. Rev. ST Accel. Beams 9, 070401 (2006).

[33] W. A. Stygar, M. E. Savage, T. C. Wagoner, L. F. Bennett, J. P. Corley, G. L. Donovan, D. L. Fehl, H. C. Ives, K. R. LeChien, G. T. Leifeste, F. W. Long, R. G. McKee, J. A. Mills, J. K. Moore, J. J. Ramirez, B. S. Stoltzfus, K. W. Struve, and J. R. Woodworth, Dielectric-breakdown tests of water at $6 \mathrm{MV}$, Phys. Rev. ST Accel. Beams 12, 010402 (2009).

[34] M. Zahn, Y. Ohki, D. B. Fenneman, R. J. Gripshover, and V. H. Gehman, Jr., Dielectric properties of water and water/ ethylene glycol mixtures for use in pulsed power system design, Proc. IEEE 74, 1182 (1986).

[35] J. C. Martin, in J. C. Martin on Pulsed Power, edited by T. H. Martin, A. H. Guenther, and M. Kristiansen (Plenum, New York, 1996).

[36] G. A. Mesyats, Pulsed Power (Springer, New York, 2004).

[37] M. L. Kiefer and M. M. Widner, SCREAMER - A single-line pulsed-power design tool, in Proceedings of the 5th IEEE International Pulsed Power Conference, edited by M. F. Rose and P. J. Turchi (IEEE, Piscataway, NJ, 1985), p. 685.

[38] R. B. Spielman, M. L. Kiefer, K. L. Shaw, K. W. Struve, and M. M. Widner, SCREAMER, A pulsed power design tool, User's guide for version 3.3.2, 2014.

[39] R. B. Spielman and Y. Gryazin, SCREAMER V4.0-A powerful circuit analysis code, in Proceedings of the 20th IEEE International Pulsed Power Conference (IEEE, Piscataway, NJ, 2015), p. 1.

[40] I. D. Smith, Induction voltage adders and the induction accelerator family, Phys. Rev. ST Accel. Beams 7, 064801 (2004). 